\title{
PICO: Testosteronsuppletie bij prostaatcarcinoom na curatieve behandeling of onder active surveillance
}

\author{
Jeroen Kolenburg $\cdot$ P. de Vries
}

Published online: 25 May 2020

(c) The Author(s) 2020

\begin{abstract}
Samenvatting Deze literatuurstudie komt voort uit een casus over testosteronsuppletietherapie (TST) bij een patiënt met curatief behandeld prostaatcarcinoom. TST is tot op heden volgens vele (internationale) richtlijnen nog gecontra-indiceerd bij behandeld of onbehandeld prostaatcarcinoom (PCa). Recente literatuur suggereert een alternatieve hypothese over het verband tussen testosteron en PCa. Na de casusbeschrijving wordt in dit artikel een overzicht gegeven van de huidige literatuur over TST bij PCa na curatieve behandeling (radicale prostatectomie, brachytherapie en uitwendige bestraling) of bij active surveillance van PCa.
\end{abstract}

Trefwoorden testosteron $\cdot$ prostaatcarcinoom $\cdot$ active surveillance

PICO: Testosterone suppletion therapy in men with curatively treated or untreated prostate carcinoma

\begin{abstract}
A patient with curatively treated prostate cancer requesting testosterone supplementation therapy (TST) provided the basis for this literature review. TST is still contraindicated according to many (international) guidelines in case of treated or untreated prostate cancer $(\mathrm{PCa})$. Recent literature suggests an alternative hypothesis on the relationship between testosterone and PCa. After the case description, an overview is given of the current literature on TST in PCa after curative treatment (radical prostatectomy, brachytherapy and external radiation) or PCa under active surveillance.
\end{abstract}

drs. J. Kolenburg $(\bowtie) \cdot$ dr. P. de Vries

afdeling Urologie, Zuyderland Medisch Centrum, Heerlen,

Sittard-Geleen, Nederland

j.kolenburg@zuyderland.nl
Keywords testosterone $\cdot$ prostate cancer $\cdot$ active surveillance

\section{Introductie}

Deze literatuurstudie komt voort uit een casus over testosteronsuppletietherapie (TST) bij een patiënt met curatief behandeld prostaatcarcinoom (PCa). TST is tot op heden volgens vele (internationale) richtlijnen nog gecontra-indiceerd bij patiënten met behandeld of onbehandeld PCa. Recente literatuur suggereert echter een alternatieve hypothese over het verband tussen testosteron en PCa.

Het doel van TST is het verbeteren van de kwaliteit van leven en het herstellen van testosteronafhankelijke functies [1]. Snyder et al. beschrijven met de T-trials de grootste $(n=788)$ placebogecontroleerde dubbelgeblindeerde trial met TST [2]. Testosteronsuppletie toonde een significant verbetering van het libido, erectiele functie, gemoedstoestand, uithoudingsvermogen en botdichtheid. Er werd geen bewezen effect gezien van TST op vermoeidheid en cognitieve symptomen.

Daarnaast is hypogonadisme geassocieerd met een verhoogd risico op cardiovasculaire ziekten [3]. Er zijn ook studies die een verband tonen tussen TST en een verhoogd risico op ernstige cardiovasculaire gebeurtenissen (MACE = major cardiovascular events) [4-6]. Deze studies hebben echter grote methodologische beperkingen en recentere onderzoeken tonen geen causaal verband tussen TST en MACE [7-9].

Contra-indicaties voor TST volgens het Farmacotherapeutisch Kompas (FK) zijn mammacarcinoom bij de man, een actieve kinderwens, hematocriet > 0,54, ernstig chronisch hartfalen en PCa. Bij laatstgenoemde vermeldt het FK tevens dat TST de progressie van subklinisch PCa kan versnellen [10]. De visie dat PCa een contra-indicatie is voor TST wordt gedeeld 
Figuur 1 Saturatiemodel waarin lijn C PCa-groei en testosteronconcentratie voorstelt. De lijnen $a$ en $b$ representeren het traditionele, lineaire stigma [21]

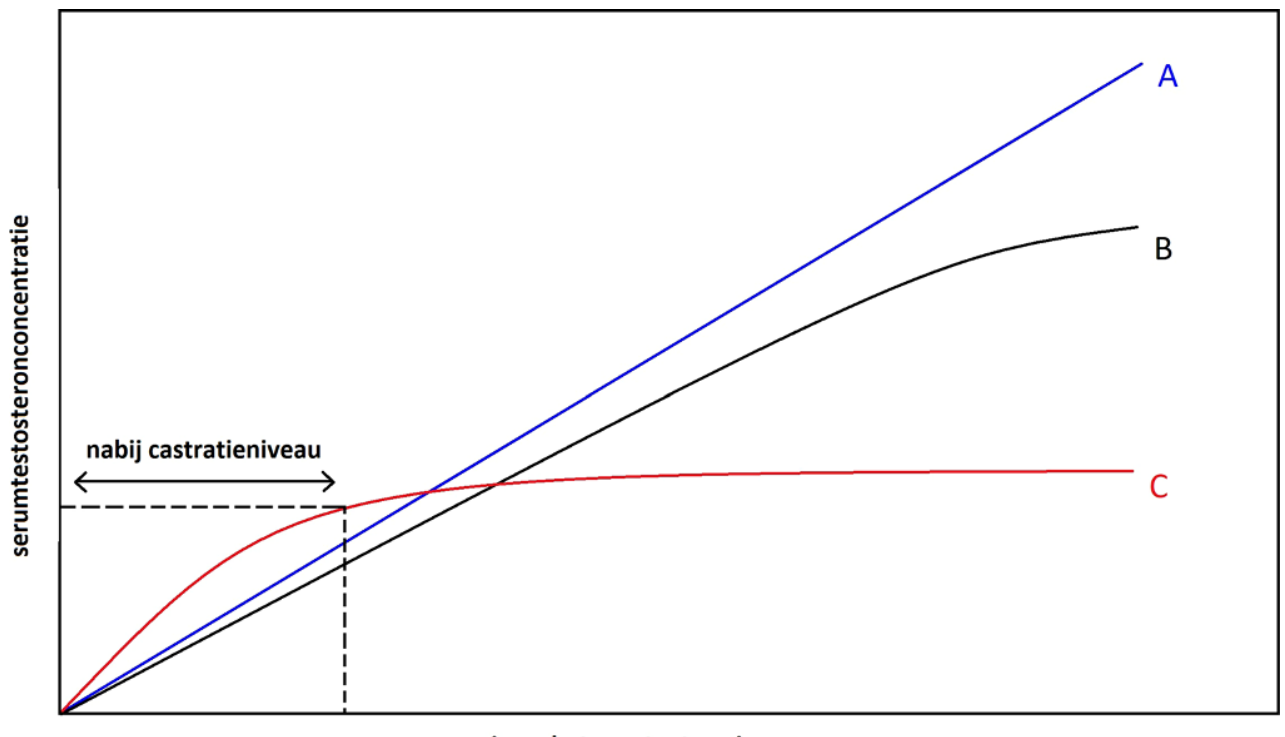

groei van het prostaatcarcinoom

met de Amerikaanse Food and Drugs Administration (FDA) [11]. De EAU stelt dat TST gecontra-indiceerd is bij lokaal gevorderd of gemetastaseerd PCa [12].

Deze visie van de FDA en het FK is deels gebaseerd op onderzoek van Huggins en Hodges uit 1941, waarvoor zij de Nobelprijs kregen [13]. Zij toonden een causaal verband aan tussen androgeenactiviteit en PCa bij (chemisch) gecastreerde patiënten door te bewijzen dat een injectie met testosteronpropionaat (TST) bij deze groep leidt tot toename van het prostaatzure fosfatase (PZF) in het serum, en dat staken van deze injecties weer leidt tot een daling daarvan. Ook andere in vitro en klinische studies suggereerden dat exogene toediening van testosteron tot stimulatie van PCa leidde bij gecastreerde patiënten, waaronder de studie van Fowler en Whitmore uit 1981 [14]. Het standpunt dat exogene TST moet worden vermeden bij gecastreerde patiënten met PCa werd vervolgens ten onrechte geëxtrapoleerd naar alle patiënten met $\mathrm{PCa}$, zowel gecastreerde als niet-gecastreerde. Deze visie werd geïmplementeerd in de geneeskunde en is de afgelopen 70 jaar vrijwel geheel onbetwist gebleven.

\section{Nieuwe signalen}

Ondanks het causale verband tussen testosteron en PCa dat werd vastgesteld halverwege de $20^{\mathrm{e}}$ eeuw, waagden enkele onderzoekers zich toch aan suppletie. In 1967 publiceerden Prout en Brewer hun onderzoek naar kortdurende (=enkele maanden) TSTbehandeling bij 26 mannen met T3, T4 of M1 PCa en 10 mannen met PCa in regressie na bilaterale orchidectomie, waarin bij slechts een van de 36 mannen het serum-PZF toenam [15]. Dit was het eerste onderzoek dat geen ongunstig effect van TST bij PCa aantoonde, hoewel de duur van follow-up kort was en de diagnostische mogelijkheden in die jaren beperkt waren. Begin deze eeuw volgde een aantal grote prospectieve cohortstudies bij gezonde patiënten waarin geen verband werd aangetoond tussen serumtestosteron en het risico op het ontwikkelen van PCa [16-20].

De relatie tussen testosteron en PCa bleek dus niet zo eenduidig als eerder gesteld. De tegenstrijdige resultaten hebben ertoe geleid dat men nieuwe, alternatieve hypothesen is gaan zoeken om de relatie tussen testosteron en PCa te kunnen verklaren.

\section{Prostaatsaturatiemodel}

In 2006 introduceerde Morgentaler een alternatieve hypothese [21], met een verfijning in 2009 [22]. De hypothese stelt: 'there is a finite ability of androgens to stimulate prostate carcinoma growth. Deze hypothese is voortgekomen uit onderzoek van Bhasin et al. [23]. Hun in-vitro-onderzoek toonde aan dat de intracellulaire androgeenconcentratie in gezond prostaatweefsel maximaal $4 \mathrm{nmol} / \mathrm{l}$ bleef, ondanks hogere serumconcentraties. Vervolgonderzoek van Marks et al. toonde in vitro aan dat deze bevinding ook toepasbaar is bij cellijnen van androgeengevoelig PCa [24]. In kwam er klinisch bewijs dat het eerder vastgestelde verband tussen testosteron en PCa bij gecastreerde mannen mogelijk ten onrechte was geëxtrapoleerd naar hypogonadale patiënten. Daarnaast werden alternatieve hypothesen opgesteld, waaronder het saturatiemodel (fig. 1).

Deze nieuwe inzichten, in combinatie met een groeiende kennis van de negatieve gezondheidseffecten en verminderde kwaliteit van leven bij mannen met testosterondeficiëntie, hebben geleid tot een paradigmaverschuiving; testosteron werd in de literatuur niet langer als directe oorzaak van PCa gezien. Dit gaf clinici een nieuwe potentiële aanpak bij de behandeling van symptomatisch hypogonadisme bij patiënten met behandeld of onbehandeld PCa. 


\section{Casus}

Deze casus betreft een 64-jarige man met in de urologische voorgeschiedenis een immatuur teratoma testis, waarvoor curatieve behandeling plaatsvond (laatste follow-up jaren geleden) en een TUR-prostaat, een cT1aN0Mx Gleason 2+3 PCa met initieel PSA 2,6 $\mu \mathrm{g} / \mathrm{l}$, waarvoor active surveillance het beleid van keuze was, maar toen in de loop van zes maanden het PSA steeg naar $5,1 \mu \mathrm{g} / \mathrm{l}$ werd besloten tot external beam radiotherapy (EBRT).

De patiënt meldde zich enkele jaren later bij zijn huisarts met een invaliderend verlaagd energieniveau, verlies van libido en erectiele disfunctie. Uit laboratoriumonderzoek bleek een lage testosteronspiegel van 4,4 nmol/l, waarop de huisarts startte met testosteronsuppletietherapie (TST), met zeer goed klinisch en biochemisch (testosteron 16,2 nmol/l) resultaat. $\mathrm{Na}$ staken van de TST werd patiënt naar de polikliniek Urologie verwezen.

Anamnestisch blijken de symptomen dermate invaliderend te zijn teruggekeerd dat hij pertinent herstart van TST wenst. Bij lichamelijk onderzoek is sprake van normale lichaamsbouw, normale lichaamsbeharing, een penis zonder afwijkingen en een kleine monotestis links. Bij rectaal toucher wordt een lege loge gevoeld. Het actuele PSA is $2,9 \mu \mathrm{g} / \mathrm{l}$ bij een nadir van $1,3 \mu \mathrm{g} / \mathrm{l}$ na EBRT. De testosteronspiegel blijkt $1,2 \mathrm{nmol} / 1$.

Om de patiënt adequaat te kunnen counselen over TST bij curatief behandeld PCa werd een literatuursearch uitgevoerd.

\section{Literatuursearch}

De zoektermen waarop de PICO werd gebaseerd, zijn: 'treated or untreated prostate carcinoma', 'hypogonadism', 'prostatecomy', 'EBRT', 'brachytherapy', 'active surveillance' (patient, P); 'testosterone suppletion', 'testosterone replacement therapy' (intervention, I); 'placebo' (control, C); 'disease progression', 'disease recurrence' (outcome, O). De search in PubMed en Google Scholar met genoemde zoektermen leverde 13 artikelen op over relevante prospectieve en retrospectieve studies op, vijf reviews en talloze case reports. De 13 artikelen zijn gesorteerd op de voorgaande of actuele behandeling van het PCa, namelijk: 1) radicale resectie van de prostaat (5 studies); 2) brachytherapie of external beam radiation therapy (EBRT) (6 studies) en 3) active surveillance (3 studies) (tab. 1). In alle studies werd TST alleen verricht bij hypogonadale patiënten.

\section{Resultaten}

\section{Radicale prostatectomie}

Dit betrof vijf studies met in totaal 203 patiënten met TST na prostatectomie, met voornamelijk laag en intermediair-risico-PCa. Bij vier van deze studies
(100 patiënten) werden geen biochemische recidieven gevonden, bij de laatste studie met 103 patiënten was sprake van een verhoogd aantal recidieven in de controlegroep ten opzichte van de patiënten die TST ontvingen, hoewel dit verschil niet significant was. De eerste studie werd gepubliceerd door Kaufman en Graydon in 2004 en rapporteerde geen biochemische recidieven na TST bij zeven mannen met voornamelijk laagrisico-PCa [25]. De gemiddelde follow-up was 24 maanden. De PSA-waarden waren na prostatectomie en gedurende de gehele follow-up onmeetbaar gebleven bij alle zeven patiënten. Agarwal en Oefelein presenteerden in 2005 hun vergelijkbare serie van 10 patiënten; deze populatie bestond echter vooral uit patiënten met intermediair-risico-PCa [26]. Ook in deze studie werd geen biochemisch recidief gevonden bij een follow-up van gemiddeld 19 maanden. In 2009 rapporteerden Khera et al. over hun veel grotere studie, bestaande uit 57 mannen met laag- en intermediair-risico-PCa. In deze studie werden de mannen na radicale prostatectomie gedurende gemiddeld 36 maanden behandeld met testosteron [27]. Na een follow-up van 13 maanden werd geen biochemisch recidief aangetoond. Kuhn et al. inventariseerden in 2015 bij 420 Beierse urologen hun ervaring met TST bij patiënten met behandeld PCa: bij 26 hypogonadale patiënten werd na prostatectomie het testosteron gesuppleerd en na mediane follow-up van 3,36 jaar werden er geen biochemische recidieven gevonden [28]. Pastuszak et al. publiceerden in 2013 de laatste studie in deze categorie met de grootste serie van 103 patiënten, van wie $25 \%$ een hoogrisico-PCa had [29]. Deze populatie vergeleken zij met een controlegroep van 49 patiënten met redelijk vergelijkbare patiëntkenmerken die geen testosteron ontvingen met een mediane follow-up van 27,5 maanden. Het PSA steeg in de behandelarm ten opzichte van de controlegroep, maar het aantal recidieven bleef in beide groepen gelijk. In deze serie van vier studies werd pas gestart met TST nadat het PSA onmeetbaar was, ongeacht de duur na operatie.

\section{Brachytherapie of EBRT}

Dit betrof zes studies met in totaal 171 patiënten na brachytherapie of EBRT, voornamelijk bij laag- en intermediair-risico-PCa. Bij vijf studies $(n=73)$ werden geen recidieven aangetoond na een gemiddelde follow-up van 41 maanden [28, 30-33]. In de vijfde studie [34] had $6,1 \%$ van de 98 patiënten een recidief, maar dit percentage ligt lager dan de algemene recidiefkans na brachytherapie of EBRT. In twee studies werden alleen patiënten met testosteron behandeld als deze eerst brachytherapie hadden ondergaan. In 2007 publiceerde Sarosdy zijn retrospectieve onderzoek van 31 mannen met voornamelijk laag-risicoPCa [30]. Er werd geen biochemisch recidief aangetoond na een mediane follow-up van vijf jaar. Balbontin et al. rapporteerden in 2011 de tweede studie naar TST na brachytherapie met 20 patiënten met 
Tabel 1 Overzicht van de studies

\begin{tabular}{|c|c|c|c|c|c|c|}
\hline $\begin{array}{l}\text { auteur(s) } \\
\text { (jaar publicatie) }\end{array}$ & land & $\begin{array}{l}\text { patiënten } \\
\text { (n) }\end{array}$ & $\begin{array}{l}\text { soort onder- } \\
\text { zoek }\end{array}$ & patiëntkenmerken & $\begin{array}{l}\text { follow-up } \\
\text { (mnd) }\end{array}$ & resultaat \\
\hline \multicolumn{7}{|l|}{ radicale prostatectomie } \\
\hline $\begin{array}{l}\text { Kaufmanen Graydon } \\
\text { (2004) [25] }\end{array}$ & VS & 7 & retrospectief & $\begin{array}{l}\text { Gl } 6 \text { en } 7 \text {; PSA onmeetbaar } \\
\text { na chirurgie en voor start } \\
\text { TST }\end{array}$ & 24 & geen biochemisch recidief \\
\hline $\begin{array}{l}\text { Agarwalen Oefelein } \\
\text { (2005) [26] }\end{array}$ & VS & 10 & prospectief & $\begin{array}{l}\text { gemiddeld PSA }<0,1 \text {; inter- } \\
\text { mediair-risico-PCa }\end{array}$ & 19 & geen biochemisch recidief \\
\hline Khera, et al. (2009) [27] & VS & 57 & retrospectief & $\begin{array}{l}\text { R0, pN0, T2; PSA }< \\
0,001 \mu \mathrm{g} / \text { /; laag- en inter- } \\
\text { mediair-risico-PCa }\end{array}$ & 13 & geen biochemisch recidief \\
\hline Kuhn, et al. (2015) [28] & Duitsland & 26 & retrospectief & $\begin{array}{l}\text { vooral Gl } 6 \text { en } 7 ; \text { PSA voor } \\
\text { start TST } 0,17\end{array}$ & 40 & geen biochemisch recidief \\
\hline Pastuszak, et al. (2013) [29] & VS & $\begin{array}{l}103+49 \\
\text { controle }\end{array}$ & retrospectief & $\begin{array}{l}25 \% \text { hoogrisico-PCa; PSA }< \\
0,004 \mu \mathrm{g} / \mathrm{l}\end{array}$ & 27,5 & $\begin{array}{l}\text { sign. PSAT behandelarm; niet-sign. } 1 \\
\text { PCa-recidieven in de controlegroep }\end{array}$ \\
\hline \multicolumn{7}{|l|}{ brachytherapie of EBRT ${ }^{a}$} \\
\hline $\begin{array}{l}\text { Kuhn, et al. (2015) [28] } \\
3 \text { brachytherapie, } 1 \text { EBRT }\end{array}$ & Duitsland & 4 & retrospectief & $\begin{array}{l}\text { vooral Gl } 6 \text { en } 7 ; \text { PSA voor } \\
\text { start TST } 0,17\end{array}$ & 40 & geen biochemisch recidief \\
\hline $\begin{array}{l}\text { Sarosdy et al. (2007) [30] } \\
\text { brachytherapie }\end{array}$ & VS & 31 & retrospectief & $\begin{array}{l}\text { Gl } 6 \text { bij } 61,3 \% \text {; stadium T1c } \\
\text { bij } 64,5 \%\end{array}$ & 60 & geen recidief-PCa \\
\hline $\begin{array}{l}\text { Balbontin, et al. (2014) [31] } \\
\text { brachytherapie }\end{array}$ & Chili & 20 & prospectief & $\begin{array}{l}\text { Gl } 6 \text { bij } 75 \% \text {; stadium T1c bij } \\
75 \% \text {; T2a bij } 25 \%\end{array}$ & 30 & $\begin{array}{l}\text { PSA gedaald van } 0,07 \text { naar } 0,01 \mu \mathrm{g} / \mathrm{l} \text {; } \\
\text { geen recidief-PCa }\end{array}$ \\
\hline $\begin{array}{l}\text { Morales, et al. (2009) [32] } \\
\text { EBRT }\end{array}$ & Canada & 5 & retrospectief & $\begin{array}{l}40 \% \text { Gl } 3+3 ; 20 \% \text { Gl } 4+3 \\
40 \% \text { Gl } 4+4\end{array}$ & 14,5 & $\begin{array}{l}\text { geen recidief-PCa; kortdurende PSA tot } \\
1,5 \mu \mathrm{g} / \mathrm{l} \text { bij } 1 \text { patiënt }\end{array}$ \\
\hline $\begin{array}{l}\text { Pastuszak (2013) [33] } \\
\text { brachytherapie/EBRT }\end{array}$ & VS & 13 & retrospectief & $\begin{array}{l}\text { laag- of intermediair-ri- } \\
\text { sico-PCa; mediaan PSA } \\
0,3 \mu \mathrm{g} / \mathrm{l}\end{array}$ & 29,7 & $\begin{array}{l}\text { geen recidief-PCa; PSAt echter niet } \\
\text { sign. }\end{array}$ \\
\hline $\begin{array}{l}\text { Pastuszak, et al. (2015) [34] } \\
\text { brachytherapie/EBRT }\end{array}$ & VS & 98 & retrospectief & $\begin{array}{l}\text { laag- of intermediair-risi- } \\
\text { co-PCa bij 76,6\% }\end{array}$ & 40,8 & $\begin{array}{l}\text { PSA } 1 \text { van } 0,08 \mathrm{naar} 0,09 \mu \mathrm{g} / \mathrm{l}(p=0,05) \\
6,1 \% \text { recidief-PCa }\end{array}$ \\
\hline \multicolumn{7}{|l|}{ active surveillance } \\
\hline $\begin{array}{l}\text { Morgentaler, et al. } \\
\text { (2011) [36] }\end{array}$ & VS & 13 & prospectief & $\begin{array}{l}92 \% \text { Gl 3+3; gemiddeld PSA } \\
5,5 \mu \mathrm{g} / \mathrm{l}\end{array}$ & 30 & $\begin{array}{l}\text { geen sign. PSA } 1 \text {; geen PCa-progressie } \\
\text { of metastasering }\end{array}$ \\
\hline Morales (2011) [37] & Canada & 7 & prospectief & $\begin{array}{l}\text { Gl } 3+3 \text { bij } 83 \% \text {; Gl } 4+4 \text { bij } \\
17 \%\end{array}$ & 19 & $\begin{array}{l}\text { PSA-kinetiek was wisselend; geen } \\
\text { biopten verricht }\end{array}$ \\
\hline Kacker, et al. (2016) [38] & VS & $\begin{array}{l}28+96 \\
\text { controle }\end{array}$ & retrospectief & Gl $3+3$ of $3+4$ & 38,9 & $\begin{array}{l}\text { minder progressie bij biopsie in de } \\
\text { behandelarm, echter niet sign. }\end{array}$ \\
\hline
\end{tabular}

tevens voornamelijk laagrisico-PCa [31]. Bij deze patiënten werd geen biochemisch recidief vastgesteld bij een mediane follow-up van 2,5 jaar. Een opvallend gegeven van deze studie is de daling van het PSA van $0,07 \mu \mathrm{g} / \mathrm{l}$ naar $0,01 \mu \mathrm{g} / \mathrm{l}$. De eerder besproken studie van Kuhn et al. bevatte tevens vier patiënten met status na brachytherapie en EBRT. Na een mediane follow-up van 3,36 jaar werd geen biochemisch recidief gevonden [28]. Morales et al. beschrijven een caseserie van vijf patiënten die werden behandeld met TST na EBRT [32]. Na een gemiddelde follow-up van 14,5 maanden werd er geen recidief-PCa aangetoond. Soortgelijke gunstige bevindingen rapporteerden ook Pastuszak et al. gemiddeld 30 maanden na brachytherapie of EBRT in hun studie met 13 mannen [33]. In 2015 publiceerden Pastuszak et al. de resultaten van brachytherapie of EBRT in een grotere multicenter retrospectieve cohortstudie ( $n=98$ ) [34]. Zoals verwacht werd na gemiddelde follow-up van 40,8 maanden bij zes patiënten $(6,1 \%)$ een biochemisch recidief vastge- steld. Belangrijk is dat de kans op biochemisch recidief na radiotherapie of brachytherapie aanmerkelijk hoger ligt (vijfjaarsprogressievrije overleving $7 \%$ ) [35]. In de hier genoemde studies startte men pas met TST nadat het PSA nadir is bereikt.

\section{Active surveillance}

In deze groep is tot op heden de minste literatuur beschikbaar. Het betrof drie studies met 48 patiënten onder active surveillance, met voornamelijk laagrisico-PCa. In één studie werd geen progressie gevonden bij 13 patiënten na mediane follow-up van 30 maanden. Een andere studie toonde bij 28 patiënten minder progressie aan in de behandelarm na een follow-up van meer dan drie maanden. De laatste studie beschreef alleen PSA-kinetiek. In al deze drie studies was een stabiel PSA een vereiste voor deelname aan de studie. Morgentaler et al. rapporteerden in 2011 zijn serie van 13 patiënten onder active surveillance met voornamelijk Gleason 6 en een gemid- 


\title{
Hier staat een advertentie.
}

\author{
cef bohn \\ stafleu \\ van loghum
}

Houten 2020 


\title{
Hier staat een advertentie.
}

\author{
cef bohn \\ stafleu \\ van loghum
}

Houten 2020 
deld PSA van 5,5 $\mu \mathrm{g} / \mathrm{L}$ die hij gemiddeld gedurende 30 maanden volgde [36]. Er werd geen significante PSA-stijging gevonden, geen progressie van het PCa bij protocollaire follow-upbiopsie en geen metastasering. In 2011 beschreef Morales een serie van zeven patiënten onder active surveillance, zonder duidelijke aanwijzingen voor biochemische progressie na gemiddeld 19 maanden; data over herbiopten werden niet gepubliceerd [37]. De meest recente studie in deze categorie is afkomstig van Kacker et al. uit 2016 die een serie onderzochten van 28 patiënten onder active surveillance. Deze patiënten toonden na 38,9 maanden minder progressie ten opzichte van de controlegroep van 96 patiënten [38]. De patiëntenpopulatie bestond uit Gleason 3+3- en 3+4-PCa met gelijke verdeling tussen de groepen.

\section{Terugkoppeling casus}

Naar aanleiding van de literatuursearch zijn de risico's van TST met de patiënt besproken. Hem is verteld dat de data tot op heden beperkt zijn, maar dat de beschikbare literatuur aantoont dat behandeling met TST geen verhoogd risico op een biochemisch recidief met zich meebrengt. Een afweging om TST aan te bieden was ook dat zijn huidige PSA aanzienlijk hoger was dan in de beschreven studies (huidig PSA $2,90 \mu \mathrm{g} / \mathrm{L}$ bij nadir $1,26 \mu \mathrm{g} / \mathrm{L}$, terwijl in studieverband vaak PSA $<1 \mu \mathrm{g} / \mathrm{L})$.

Gezien zijn invaliderende klachten gaf patiënt consent om TST te herstarten in de vorm van testosterongel. Tevens kreeg hij leefstijladviezen. Er zal driemaandelijkse poliklinische controle plaatsvinden met lichamelijk en laboratoriumonderzoek.

\section{Discussie}

Er bestaat in de literatuur nog veel discrepantie betreffende de inclusiecriteria voor de start van TST bij PCa na actieve behandeling of onder active surveillance. Tot op heden bestaan hier geen richtlijnen voor. Op basis van de literatuur is ons voorstel om allereerst niet-medicamenteus te interveniëren door leefstijladviezen te geven [1]. Indien medicamenteuze behandeling geïndiceerd is, lijkt het op basis van de huidige literatuur veilig om het testosterongehalte tot normaalwaarde te suppleren bij patiënten met een laag of intermediair risico bij wie geen sprake is van een biochemisch recidief.

Een beperking van de huidige literatuur over TST is allereerst de korte follow-up (gem. slechts 31 maanden) voor uitkomstmaten zoals biochemisch recidief en kankerspecifieke overleving. Daarnaast betreft het alleen cohortonderzoeken, waarvan vele retrospectief. Ten slotte, het aantal geïncludeerde patiënten, met name in de groep van active surveillance, is vrij beperkt. Dit komt mede voort uit het beperkt aantal studies in deze groep. Deze beperkingen dienen te worden meegenomen in de klinische besluitvorming.
Het feit dat het resultaat van veel recent verschenen literatuur strijdig is met de eerdere consensus over TST bij PCa, roept interessante vragen op. Bijvoorbeeld over het suppleren van testosteron bij patiënten met een biochemisch recidief na lokale behandeling. Onze hypothese is dat het suppleren van testosteron tot de normaalwaarde bij een hypogonadale patiënt geen verhoogd risico op progressie geeft ten opzichte van het risico op progressie bij een patiënt met een normale testosteronconcentratie. Als deze hypothese klopt, zou TST veilig zijn bij alle hypogonadale patiënten met PCa, zolang er geen indicatie is voor androgeendeprivatie. Immers, als men geen testosteron onttrekt aan een normogonadale patiënt met PCa, waarom zou men dan een hypogonadale patiënt met PCa testosteron moeten onthouden?

\section{Conclusie}

Bestaande literatuur lijkt sterk te suggereren dat TST tot de normaalwaarde bij patiënten met PCa veilig is. Langetermijndata en aanvullende, gerandomiseerde studies zijn echter nodig om het stigma rond TST en PCA definitief de wereld uit te helpen. Op het moment dat bij een patiënt castratie wordt nagestreefd, zal de TST uiteraard moeten worden gestaakt.

Open Access This article is distributed under the terms of the Creative Commons Attribution 4.0 International License (http://creativecommons.org/licenses/by/4.0/), which permits unrestricted use, distribution, and reproduction in any medium, provided you give appropriate credit to the original author(s) and the source, provide a link to the Creative Commons license, and indicate if changes were made.

\section{Literatuur}

1. Maatje MGF, Dinkelman-SmitM, BoellaardWPA, DohleGR. Testosterontherapie: indicaties en risico's. Ned Tijdschr Geneeskd. 2018;162:D1947.

2. Snyder PJ, Bhasin S, Cunningham GR, et al. Effects of testosterone treatment in older men. N Engl J Med. 2016;374:611-24.

3. Zarotsky V, Huang MY, Carman W, Morgentaler A, Singhal PK, Coffin D, etal. Systematicliterature review of the riskfactors, comorbidities, and consequences of hypogonadism in men. Andrology. 2014;2:819-34.

4. Basaria S, Coviello AD, Travison TG, Storer TW, Farwell WR, Jette AM, et al. Adverse events associated with testosterone administration. NEnglJ Med. 2010;363:109-22.

5. Finkle WD, Greenland S, Ridgeway GK, Adams JL1, Frasco MA1, Cook MB, et al. Increased risk of non-fatal myocardial infarction following testosterone therapy prescription in men. PLoSOne. 2014; 9:e85805.

6. Vigen R, ODonnell CI, Barón AE, Grunwald GK, Maddox TM, Bradley SM, et al. Association of testosterone therapy with mortality, myocardial infarction, and stroke in men with low testosteronelevels. JAMA. 2013;310:1829-36.

7. Sharma R, Oni OA, Gupta K, Chen G3, Sharma M1, Dawn B, et al. Normalization of testosterone level is associated with reduced incidence of myocardial infarction and mortality in men. Eur Heart J. 2015;36:2706-15. 
8. Anderson JL, May HT, Lappé DL, Bair T, Le V, Carlquist JF, et al. Impact of testosterone replacement therapy on myocardial infarction, stroke, and death in men with low testosterone concentrations in an integrated health care system. Am J Cardiol. 2016;117(5):794-9.

9. Wallis CJ, Lo K, Lee Y, Krakowsky Y1, Garbens A1, Satkunasivam R, et al. Survival and cardiovascular events in men treated with testosterone replacement therapy: an intention-to-treat observational cohort study. Lancet Diabetes Endocrinol. 2016;4:498-506.

10. Farmacotherapeutisch Kompas. Testosteron. Beschikbaar via https://www.farmacotherapeutischkompas.nl/ bladeren/preparaatteksten/t/testosteron\#extra-info. Geraadpleegd op: 3 dec 2019.

11. U.S. Food and Drug Administration. FDA drug safety communication. FDA cautions about using testosterone products forlow testosterone due to aging; requires labeling change to inform of possible increased risk of heart attack and stroke with use. Silver Spring (VS):FDA; 2019.

12. DohleGR, ArverS, BettocchiC, Jones TH, Kliesch S. Malehypogonadism. Guideline European Association of Urology. 2018.

13. Huggins C, Hodges CV. Studies on prostatic cancer. I. The effect of castration, of estrogen and of androgen injection on serum phosphatases in metastatic carcinoma of the prostate. 1941. JUrol. 2002;167:948-51. discussion 952.

14. Fowler JE Jr, Whitmore WF Jr.. The response of metastatic adenocarcinoma of the prostate to exogenous testosterone. JUrol. 1981;126:372-5.

15. Prout GR Jr, Brewer WR. Response of men with advanced prostatic carcinoma to exogenous administration of testosterone. Cancer. 1967;20:1871-8.

16. Khera M, Crawford D, Morales A, Salonia A, Morgentaler A. Anew era of testosterone and prostate cancer: from physiology to clinical implications. Eur Urol. 2014;65(1):115-23.

17. Cooper CS, Perry PJ, Sparks AE, MacIndoe JH, Yates WR, Williams RD. Effect of exogenous testosterone on prostate volume, serum and semen prostate specific antigen levels in healthy young men. J Urol. 1998;159:441-3.

18. Bhasin S, Storer TW, Brman N, et al. The effects of supraphysiologic doses of testosterone on muscle size and strength in normal men. NEngl J Med. 1996;335:1-7.

19. Monath JR, McCullough DL, Hart LJ, Jarow JP. Physiologic variations of serum testosterone within the normal range do not affect serum prostate-specific antigen. Urology. 1995;46:58-61.

20. Shin BS, Hwang EC, Im CM, Kim SO, Jung SI, Kang TW, et al. Is a decreased serum testosterone level a risk factor for prostate cancer? A cohort study of Korean men. Korean J Urol. 2010;51:819-23.

21. Morgentaler A. Testosterone and prostate cancer: an historical perspective on a modern myth. Eur Urol. 2006;50:935-9.

22. Morgentaler A, Traish AM. Shifting the paradigm of testosterone and prostate cancer: the saturation model and the limits of androgen-dependent growth. Eur Urol. 2009;55:310-21.

23. Bhasin S, Cunningham GR, Hayes FJ, Matsumoto AM, Snyder PJ, Swerdloff RS, et al. Testosterone therapy in men with androgen deficiency syndromes: an Endocrine Society clinical practice guideline. Clin Endocrinol Metab. 2010;95:2536-59.
24. Marks LS, Mazer NA, Mostaghel E, Hess DL, Dorey FJ, Epstein JI, et al. Effect of testosterone replacement therapy on prostate tissue in men with late-onset hypogonadism: a randomized controlled trial. JAMA. 2006;296(19):2351-61.

25. Kaufman JM, Graydon RJ. Androgen replacement after curative radical prostatectomy for prostate cancer in hypogonadal men. JUrol. 2004;172(3):920-2.

26. Agarwal PK, Oefelein MG. Testosterone replacement therapy after primary treatment for prostate cancer. J Urol. 2005;173(2):533-6.

27. Khera M, Grober ED, Najari B, Colen JS, Mohamed O, Lamb DJ, et al. Testosterone replacement therapy following radical prostatectomy. J SexMed. 2009;6(4):1165-70.

28. Kühn CM, Strasser H, Romming A, Wullich B, Goebell PJ. Testosterone replacement therapy in hypogonadal men following prostate cancer treatment: a questionnaire-based retrospective study among urologists in Bavaria, Germany. Urol Int. 2015;95(2):153-9.

29. Pastuszak AW, Pearlman AM, Lai WS, Godoy G, Sathyamoorthy K, Liu JS, et al. Testosterone replacement therapy in patients with prostate cancer after radical prostatectomy. JUrol. 2013;190(2):639-44.

30. Sarosdy MF. Testosterone replacement for hypogonadism after treatment of early prostate cancer with brachytherapy. Cancer. 2007;109(3):536-41.

31. BalbontinFG, MorenoSA, BleyE, ChaconR, SilvaA, Morgentaler A. Long-acting testosterone injections for treatment of testosterone deficiency after brachytherapy for prostate cancer. BJU Int. 2014;114(1):125-30.

32. Morales A, Black AM, Emerson LE. Testosterone administration to men with testosterone deficiency syndromeafter external beam radiotherapy for localized prostate cancer: preliminary observations. BJU Int. 2009;103(1):62-4.

33. Pastuszak AW, Pearlman AM, Godoy G, Miles BJ, Lipshultz LI, Khera M. Testosterone replacement therapy in the setting of prostate cancer treated with radiation. Int J Impot Res. 2013;25(1):24-8.

34. Pastuszak AW, Khanna A, Badhiwala N, Morgentaler A, Hult M, Conners WP, Sarosdy MF, et al. Testosterone therapy after radiation therapy for low, intermediate and high risk prostate cancer. J Urol. 2015;194(5):1271-6.

35. Zelefsky M, Yamada Y, Fuks Z, Zhang Z, Hunt M, Cahlon $\mathrm{O}$, Park, et al. Long-term results of conformal radiotherapy for prostate cancer: impact of dose escalation on biochemical tumor control and distant metastases-free survival outcomes. Int J Radiat Oncol Biol Phys. 2008;71(4):1028-33.

36. Morgentaler A, Lipshultz LI, Bennett R, Sweeney M, Avila D, Khera M. Testosterone therapy in men with untreated prostate cancer. JUrol. 2011;185(4):1256-60.

37. Morales A. Effect of testosterone administration to men with prostate cancer is unpredictable: a word of caution and suggestions for a registry. BJU Int. 2011;107(9):1369-73.

38. Kacker R, Hult M, San francisco IF, Conners WP, Rojas PA, DewolfWC, et al. Can testosterone therapy be offered to men on active surveillance for prostate cancer? Preliminary results. Asian JAndrol. 2016;18(1):16-20.

drs. Jeroen W.C. Kolenburg, arts-assistent urologie

dr. P. de Vries, uroloog 